\title{
Erratum to: Physical structure and thermal behavior of ethylcellulose
}

M. Davidovich-Pinhas $\cdot$ E. D. Co $\cdot$ S. Barbut $\cdot$

A. G. Marangoni

Published online: 28 March 2015

(C) Springer Science+Business Media Dordrecht 2015

Erratum to: Cellulose (2014) 21:3243-3255 DOI 10.1007/s10570-014-0377-1

In the original publication of the article, the intuitional author "Edmund Daniel Co" was omitted inadvertently. The complete author list is provided here. 